\title{
AS CONTRIBUIÇÕES DO PIBID NO ENSINO DE QUÍMICA: ATIVIDADES ALTERNATIVAS A PARTIR DA CONFECÇÃO DE FERRAMENTAS PEDAGÓGICAS PROVENIENTES DE MATERIAIS DE BAIXO-CUSTO
}

\author{
N.V. Araúuo, F. G. F. Santos, I. C. A. Costa, M. S. Albuquerque, D. S. Silva \\ Universidade Estadual Vale do Acaraú (UVA) \\ <naiaraveras@gmail.com>,<giovanni_fs2008@hotmail.com>,<izabelcosta08@gmail.com> \\ $<$ marilene_albuquerque@outlook.com><draulio4000@yahoo.com.br $>$ \\ DOI: $10.21439 /$ conexoes.v10i4.981
}

\begin{abstract}
Resumo. Estudos científicos apontam que o Ensino em Química, na sua grande maioria, é tradicionalista concentrando-se na repetição de nomes, fórmulas e cálculos, o que gera no aluno desconcentração e falta de motivação, levando-os a questionar o porquê de estar estudando determinados conteúdos. Observa-se de forma intensa a desmotivação dos estudantes por parte da Química, quando trata de assuntos extensos e nada atrativos na visão de muitos, como é o caso da tabela periódica. Atualmente, professores e pesquisadores em Educação Química estão utilizando jogos lúdicos como proposta facilitadora para o processo de ensino-aprendizagem dos conceitos em Química. Conjugando tais metodologias ao uso de materiais de baixo custo e fácil acesso. Neste sentido, o presente trabalho resultou de uma atividade desenvolvida com alunos do ensino médio, em uma escola parceira do Programa Institucional de Bolsas de Iniciação à Docência - PIBID. Trabalho este, realizado por acadêmicos do curso de Licenciatura em Química. A avaliação da influência da atividade lúdica na aprendizagem foi feita por meio de questionários, que avaliaram a fixação do conteúdo e aceitação do jogo por parte dos alunos. Esses resultados foram graficamente representados, mostrando que a atividade lúdica teve influência positiva no processo de aprendizagem do conteúdo de tabela periódica. O artigo retrata os resultados na análise da atividade desenvolvida, buscando refletir sobre o uso de novas estratégias, para que o Ensino de Química se torne algo prazeroso e divertido para os discentes, possibilitando o desenvolvimento social dos estudantes no tocante à cooperação, competição e trabalho em equipe.
\end{abstract}

Palavras-chaves: Aulas alternativas. Ensino de Química. PIBID.

\begin{abstract}
Scientific studies show that Teaching in Chemistry, for the most part, is traditionalist concentrating on the repetition of names, formulas and calculations, which generates in the student deconcentration and lack of motivation, leading them to question why they are studying certain Content. The students' lack of motivation on the part of Chemistry is intense, when it deals with long and unattractive subjects in the eyes of many, as is the case with the periodic table. Currently, professors and researchers in Chemical Education are using play games as a facilitating proposal for the teaching-learning process of concepts in chemistry. Combining such methodologies with the use of materials of low cost and easy access. In this sense, the present work resulted from an activity developed with high school students, in a partner school of the Institutional Program of Teaching Initiation Scholarships - PIBID. Work, this, carried out by academics of the course of Degree in Chemistry. The evaluation of the influence of play activity on learning was done by means of questionnaires, which evaluated the content fixation and acceptance of the game by the students. These results were graphically represented showing that the play activity had a positive influence on the learning process of the periodic table content. The article portrays the results in the analysis of the activity developed, seeking to reflect on the use of new strategies, so that the Teaching of Chemistry becomes something pleasant and fun for the students, enabling the students' social development regarding cooperation, competition and work in a team.
\end{abstract}

Keywords: Alternative classes. Chemistry Teaching. PIBID. 


\section{INTRODUÇÃO}

O Ensino de Química, assim como o de biologia, física e matemática tem sido um verdadeiro desafio para os futuros e novos docentes. Segundo Cunha (2012), por longas décadas acreditou-se que a aprendizagem ocorria pela repetição e que os estudantes que não aprendiam eram os únicos responsáveis pelo seu insucesso. Hoje em dia, o insucesso do aluno também é considerado como consequência do trabalho do professor. Passa a ser competência do docente a ideia do ensino despertado pelo interesse do estudante. Desse modo, é notável a quantidade de discussões referentes às dificuldades encontradas na formação inicial de professores, para que estes novos docentes sejam capazes de estimular seus discentes:

Caracterizando-se por ser um tema de alta complexidade, seja no âmbito dos cursos de graduação ou nas pesquisas científicas, esse tema envolve, dentre outros aspectos, a dimensão profissional e a iniciação à docência. Trata-se de duas fases de muitos desafios para o professor principiante, assim como para seus formadores. Tais desafios tornam-se mais acentuados diante de uma profissão com pouco reconhecimento social e, consequentemente, com baixa atratividade aos jovens ingressantes nas universidades (DANTAS. 2013).

Diante desta realidade, buscam-se constantemente melhorias visando à maneira como a disciplina pode ser ministrada, principalmente nos anos iniciais do ensino médio, com isto a utilização de atividades lúdicas como ferramentas no processo de ensino-aprendizagem, tem ganhado cada vez mais espaço, possibilitando resultados bastante significativos no que diz respeito à aceitação por parte dos alunos, simplicidade e compreensão no repasse dos conteúdos.

De acordo com (BROWN et al.,2005, p.2), para que haja compreensão no Ensino de Química deve ocorrer a junção da teoria e da prática, fazendo uso de objetos de baixo custo e de fácil acesso, de uma forma que desperte no aluno curiosidade e o faça relacionar aquilo que lhe foi apresentado com os acontecimentos do cotidiano, pois a Química trata-se de uma ciência extremante prática que tem grande impacto no dia-a-dia.

Buscando aprimorar a formação inicial do docente, o Programa Institucional de Bolsas de Iniciação à Docência - PIBID tem como uma de suas finalidades possibilitar que acadêmicos de IES estejam mais presentes no ambiente escolar, conhecendo assim, sua realidade de trabalho. Tal experiência resultará num acúmulo de saberes que posteriormente servirá como facilitador nas tomadas de decisões que envolvam a sala de aula. $\mathrm{O}$ interesse obtido pela prática da pesquisa durante a estadia no PIBID implica em um desenvolvimento de atividades alternativas e inovadoras. E graças à maneira como o programa encaminha suas competências aos bolsistas, surgem aptidões de grande relevância, como habilidades de comunicação e domínio de linguagem, que resultam numa melhor articulação dos possíveis meios de ensino que se desenvolverão.

O PIBID vem se tornando uma política pública muito importante de valorização do magistério, possibilitando aos licenciandos atuação no seu campo de trabalho, desde o início de sua formação, por meio de atividades que possibilitam a interação com professores e estudantes da educação básica e a articulação entre a universidade e as escolas (DANTAS, 2013).

Diante da possibilidade de vivência na escola que o PIBID oferece aos bolsistas, podemos destacar uma gama de valores que são adquiridos, tais como: familiaridade prévia com a futura profissão, maior possibilidade de análise crítica de sua atuação como docente e, a partir daí, aprimoramento na função de futuro professor.

O ensino de Química, para ser bem articulado, deve conter em sua matriz curricular assuntos relacionados ao cotidiano dos discentes, algo que lhes permita visualizar de maneira clara e objetiva a resolução de problemas, que lhes faça compreender o mundo que os cerca e principalmente "deve possibilitar ao aluno a compreensão tanto dos processos químicos em si quanto da construção de um conhecimento científico em estreita relação com as aplicações tecnológicas e suas implicações ambientais, sociais, políticas e econômicas" (BRASIL. 1999, p.31)

A partir da realidade presenciada nos sistemas de ensino, o uso de diferentes alternativas deve ser uma realidade, pois na disciplina de Química o uso de materiais de fácil acesso e baixo custo tem significativa contribuição, desde que sejam utilizados da maneira correta servindo como ferramentas de ensino. É válido ressaltar que a forma tradicional tem seu valor primordial, pois a teoria deve ser repassada, mas não se limitar à única e exclusiva metodologia aplicada nas escolas públicas, principalmente no ensino médio.

A inserção da prática reflexiva durante o processo de formação inicial fornecerá ao futuro professor opções e possibilidades para a construção de sua identidade profissional no decorrer de sua formação, tornando-o capaz de refletir a respeito de sua prática de maneira crítica, de ver sua realidade de sala de aula para além do conhecimento na ação e de responder, reflexivamente, aos problemas relacionados à profissão docente (MALDANER 2006. SCHÖN 2000

Para que se possa obter um resultado significativo ao utilizar as atividades alternativas no Ensino de Química, deve-se tentar buscar maior proximidade no âmbito de 
AS CONTRIBUIÇÕES DO PIBID NO ENSINO DE QUÍMICA: ATIVIDADES ALTERNATIVAS A PARTIR DA CONFECÇÃO DE FERRAMENTAS PEDAGÓGICAS PROVENIENTES DE MATERIAIS DE BAIXO-CUSTO

facilitar a compreensão por parte dos alunos em relação ao método que se deseja aplicar. Para isto, se faz necessário um detalhamento do material a ser utilizado, seguido do desenvolvimento da confecção da nova ferramenta de ensino, juntamente com um prévio conhecimento das habilidades dos alunos, para que se possa identificar o grau de complexidade que essa atividade pode alcançar. Deste modo, após a sua confecção ele se tornará um meio didático correlacionado ao conteúdo químico em questão, trazendo informações relevantes aos alunos, apresentando semelhanças a outras metodologias de simples entendimento, passando a ser inovador, originado a partir da utilização de objetos de baixocusto.

\section{METODOLOGIA}

\subsection{Caracterização}

A atividade pedagógica foi aplicada para alunos do $1^{o}$ ano do ensino médio da Escola CERE Prefeito José Euclides Ferreira Gomes Júnior, na bairro Alto do Cristo na cidade de SobralCE. Funciona nos períodos matutino, vespertino e noturno, atendendo cerca de 800 alunos matriculados entre os anos finais do ensino médio. A atividade intitulada "Tabela Periódica Animada" foi desenvolvida no decorrer do segundo semestre de 2014 envolvendo turmas do $1^{\circ}$ ano e três alunos do $3^{o}$ ano do ensino médio, alunos estes, que não tinham bom aproveitamento nas avaliações que lhes eram atribuídas, e que demonstravam desinteresse pelas aulas, totalizando um público-alvo de 93 alunos.

\subsection{Justificativas De Desenvolver Uma Tabela Pe- riódica Diferenciada}

A Tabela Periódica é de grande importância no desenvolvimento da formação discente, por se tratar de um conteúdo que é praticamente a base para os subsequentes assuntos. Diante disso, saber fazer a interpretação da mesma é fundamental para conhecer e compreender os elementos químicos e suas características físicas e químicas.

Sabendo de tal importância, para proporcionar melhor compreensão do conteúdo em questão foi proposta a criação de uma atividade lúdica embasada nos conceitos de Tabela Periódica para o desenvolvimento do aluno. A partir deste fato, surgiu a ideia de confeccionar uma Tabela Periódica diferente, juntamente com a participação de alguns alunos da escola parceira do PIBID, em que ao invés de se colocar os elementos químicos que tradicionalmente são apresentados com suas características a mostra, foram colocadas figuras que representassem os mesmos, em que cada imagem apre- sentava uma aplicação do elemento, em que esta era de conhecimento dos discentes.

\subsection{Intervenção}

É importante salientar uma ação que contribuiu significativamente para a elaboração da atividade, a escolha de três alunos do $3^{\circ}$ ano, que possuíam um baixo rendimento, para confeccionarem e repassar a atividade para os demais alunos. Buscando avaliá-los diante de um conteúdo já visto, mas com intenção de verificar como se sairiam ao deparar-se novamente com tal assunto e principalmente a maneira como encarariam a avaliação que lhes foi proposta, proporcionando-lhes a chance de se colocarem na condição de professor.

\subsection{Procedimentos para a confecção do objeto di- dático}

O desenvolvimento da tabela foi organizado em duas etapas, que consistiu na divisão das tarefas a serem realizadas, a primeira foi a escolha das imagens que representariam cada elemento químico e outras informações que caracterizassem o mesmo. A segunda foi a confecção da tabela propriamente dita, com o auxílio de três discentes da escola na qual foi realizada a atividade, finalizando com a exposição aos demais alunos da escola. Períodos de cinquenta minutos, num total de cinco períodos foram utilizados para a aplicação das atividades.

Para a confecção da tabela foram utilizados materiais de baixo custo: isopor, papel madeira, cola branca, figuras retiradas de jornais, revistas e internet, cartas pré-selecionadas - confeccionadas impressas em papel A4 (contendo informações relevantes de cada elemento químico), tesoura e pincel atômico. Durante a confecção, revestiu-se o isopor com papel madeira, para facilitar a adesão das figuras, em seguida utilizando-se papel madeira, criou-se um pequeno compartimento em formato retangular (uma espécie de bolso), que foi fixado sobre o isopor, já revestido, permitindo que as imagens fossem afixadas sobre o "bolso", e dentro houvesse uma carta pré-selecionada, com os dados do elemento químico em questão, por exemplo, símbolo, número atômico, sua utilização (além da representada na imagem) e sua ocorrência na natureza. A Figura 1 mostra um dos alunos, que participou da confecção da "Tabela Periódica Animada", segurando a atividade lúdica com algumas cartas à mostra (cartas estas, que já haviam sido identificadas pelos alunos), as demais cartas, encontravam-se viradas, só sendo possível visualizá-las após a identificação da imagem pelos alunos. 


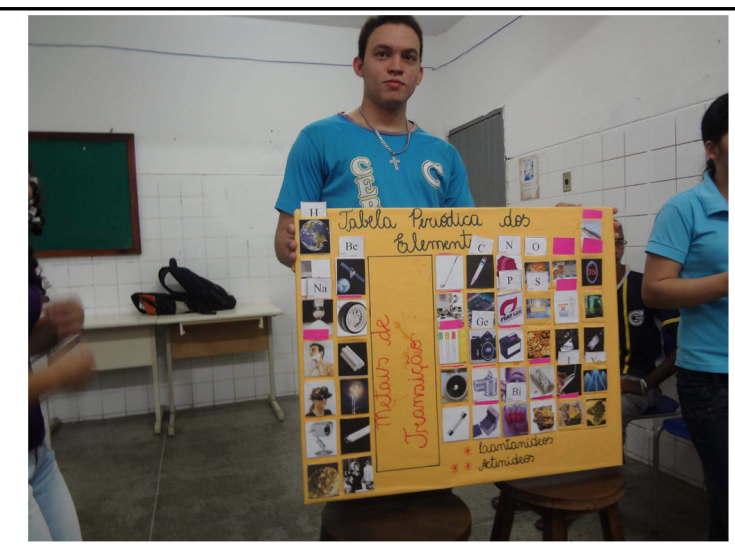

Figura 1: Tabela Periódica Animada com algumas cartas à mostra Fonte: Arquivo pessoal

\subsection{Aplicação da atividade aos alunos da escola parceira do PIBID}

Os elementos trabalhados foram apenas representativos, pois são os mais vistos na disciplina de Química no ensino médio. A "Tabela Periódica Animada" foi apresentada aos alunos do $1^{\circ}$ ano do ensino médio da escola parceira, após ter sido explicada e apresentada aos alunos do $3^{\circ}$ ano, havendo breve explanação sobre o assunto abordado, tiraram-se algumas dúvidas que ainda persistiam, para que eles viessem a ter uma melhor compreensão da atividade, facilitando seu repasse aos demais discentes.

Seguindo com o procedimento da atividade, os alunos deveriam escolher uma figura na tabela e tentar descobrir qual elemento ela representava, logo após a escolha, caso eles conseguissem identificar o elemento químico ou não, uma explicação sobre a figura e as informações contidas atrás da imagem no compartimento era apresentada aos alunos. Sabe-se que a Química é uma ciência em partes abstrata, pois mesmo sendo possível explicar seus conceitos e teorias a partir de diversas situações cotidianas, algumas aplicações apresentam certa dificuldade de identificação. Uma delas é a presença de elementos químicos de certo modo desconhecidos em materiais de uso frequente ou do conhecimento das pessoas, por este motivo foram utilizadas figuras para se fazer a representação dos elementos químicos da tabela. No ano de 2006, Giacomini et al. (2006) abordam o ato de ensinar explicitando que,

Mesmo reconhecendo que o ato de ensinar deve ser tão antigo quanto à existência do próprio homem, observamos que ainda há uma preocupação constante dos educadores no desenvolvimento de procedimentos de ensino que possam disponibilizar o conhecimento da maneira mais clara e eficiente possível.

\section{RESULTADOS E DISCUSSÃO}

A aquisição de uma Tabela Periódica diferenciada em sala de aula resultou em uma inovação no âmbito de ensino aprendizagem. Por sua apresentação simples e objetiva, possibilita ao professor utilizá-la como ferramenta auxiliar de ensino. Observou-se que os alunos demonstraram grande curiosidade durante a aplicação da atividade, buscando descobrir qual elemento estava por trás das figuras, e se surpreendendo com o fato de ser algo tão próximo a sua realidade.

A disposição dos elementos sendo representados por imagens do cotidiano dos alunos foi uma maneira de dar ênfase às suas aplicações no dia-a-dia, além das diversas características pertinentes da cada elemento representativo. Um ponto a se destacar foi a contribuição dada por três alunos do $3^{\circ}$ ano do ensino médio, foi possível observar o desempenho positivo de ambos, pois adquiriram um conhecimento, além de terem a oportunidade de relembrar o assunto visto por eles em anos anteriores e principalmente puderam repassar tais conhecimentos para os demais e com aproveitamento satisfatório, haja vista os resultados obtidos nos questionários resolvidos pelos alunos. A Figura 2 mostra de forma clara o objeto de ensino concluído.

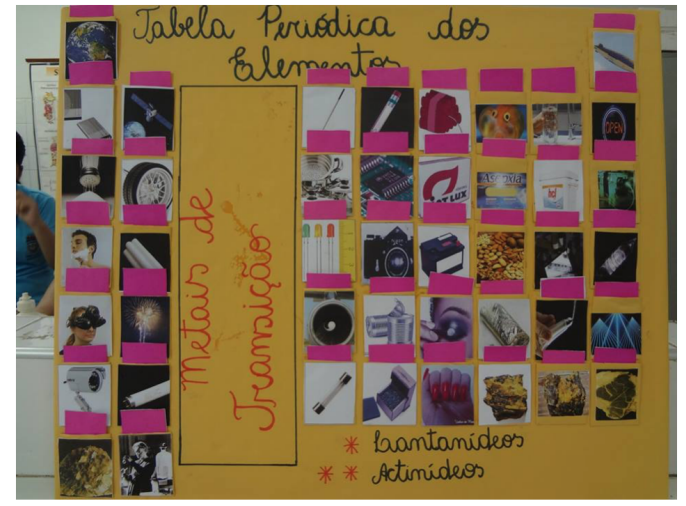

Figura 2: Tabela Periódica Animada concluída. As cartas contendo as informações dos elementos se apresentam na cor rosa. Fonte: Arquivo pessoal.

A implantação de novos métodos de repassar o conteúdo de Química é uma forma de auxiliar no âmbito da compreensão de tais conceitos e faz com que a disciplina seja vista com mais clareza, pois ao abordar informações da área associadas com situações mais próximas dos alunos e presentes em objetos de seu conhecimento, torna o aprendizado efetivo por caracterizar uma abrangência maior entre o que se pretende ensinar e exemplos que se relacionem com o objetivo em questão. "As orientações e os parâmetros curriculares para o ensino médio (PCNEM) buscam direcionar pro- 
fessores a procurar novas abordagens para o tratamento conceitual sempre de forma interdisciplinar" (BRASIL 2006).

A abordagem dos conceitos de Tabela Periódica feita com a representação por meio de imagens de materiais constituídos pelos seus respectivos elementos químicos despertou uma nova maneira de ver a tabela em si, não considerando apenas os símbolos atômicos como parâmetro para a identificação, mas destacando também a importância das demais características dos elementos químicos, inicialmente de uma forma implícita, pois o número atômico presente nas cartas define a posição de determinado elemento na tabela periódica, o que levou a busca da compreensão de que as informações numéricas das tabelas usuais têm importância acentuada, já que determinam as propriedades físicas e químicas de cada elemento químico auxiliando na produção de materiais do cotidiano.

\footnotetext{
As informações contidas na tabela geralmente são apenas decoradas pelos alunos, que acabam não compreendendo as propriedades periódicas e aperiódicas, a localização dos elementos e como essas propriedades se relacionam para a formação das substâncias (GODOI; OLIVEIRA; CODOGNOTO 2010).
}

Durante a aplicação da atividade e percebeu-se a fixação dos conteúdos de Tabela Periódica por parte dos alunos. Tais resultados foram constatados a partir da correção dos questionários aplicados verificando o nível de aceitação por parte dos discentes a partir da avaliação feita por eles em relação à atividade, como também foi possível perceber alguns detalhes que podem ser melhorados, os dados da análise serão apresentados a seguir.

A primeira pergunta "O que você achou da atividade apresentada?" partiu do pressuposto de que os alunos expusessem a sua opinião sobre o método utilizado no repasse das informações sobre a tabela periódica. Para responderem a esta questão dispunham de quatro opções de múltipla escolha: Regular que teve uma porcentagem de 5\%. Bom com 85\%. Ótimo com 7\%. Ruim com apenas 3\%. A Figura 3 representa a avaliação feita pelos alunos acerca da atividade que lhes foi aplicada.

Uma ideia defendida por Astolfi, Develay e Fonseca (1995) é que:

Qualquer que seja a concepção metodológica a ser seguida, os saberes desenvolvidos no ensino de Química devem ser fundamentados em estratégias que estimulem a curiosidade e a criatividade dos estudantes, despertando sua sensibilidade para a inventividade e compreendendo que esta ciência e seus conhecimentos permeiam a sua vida, estando presentes nos fenômenos mais simples do seu cotidiano.

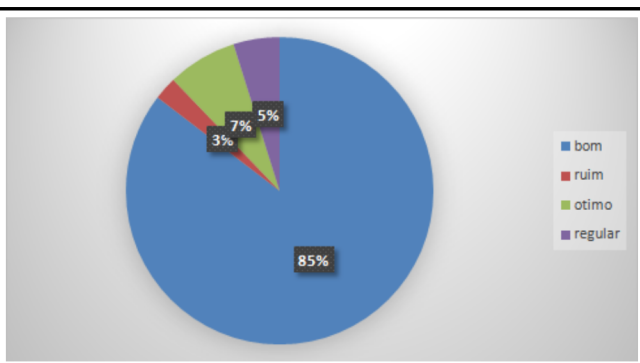

Figura 3: Gráfico de opiniões dos alunos quanto ao método de aplicação da atividade.

A segunda pergunta era a seguinte: "A metodologia utilizada foi repassada com clareza?", visando a maneira de como seria repassado o procedimento da atividade, bem como as informações necessárias aos alunos do conteúdo em questão. As respostas dos discentes indicaram uma positividade neste quesito, totalizando $100 \%$ dos que assinalaram a opção referente à clareza, considerando a opinião dos mesmos.

A terceira questão: "Você acha que as aulas ficam mais atrativas com a utilização de atividades lúdicas?", que atribuía a conexão desta prática com a assimilação do conteúdo, a Figura 4 mostra que $87 \%$ dos alunos afirmaram ter aumentado sua compreensão sobre o tema abordado associado ao método lúdico utilizado, e $13 \%$ responderam que não. Com os dados explicitados observa-se que o uso de novas metodologias no ensino de Química deixa claro que é necessário a utilização cada vez mais constante de aulas inovadoras, assim como ANTUNES (2002), afirma que:

A atual geração requer novas ferramentas metodológicas para não perder o foco do aprendizado. Já que as ferramentas tradicionais de ensino não possuem uma eficácia motivadora e dinâmica quando se refere ao ensinoaprendizagem de Ciências.

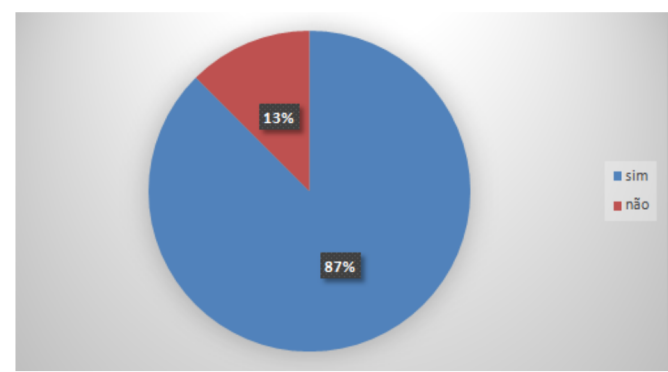

Figura 4: Gráfico referente à assimilação do conteúdo por parte dos discentes.

Na quarta questão foi solicitado aos alunos que atribuíssem uma nota de avaliação para a atividade na qual 
AS CONTRIBUIÇÕES DO PIBID NO ENSINO DE QUÍMICA: ATIVIDADES ALTERNATIVAS A PARTIR DA CONFECÇÃO DE FERRAMENTAS PEDAGÓGICAS PROVENIENTES DE MATERIAIS DE BAIXO-CUSTO

participaram, seguido de uma justificativa, observou-se por meio das notas e justificativas que algo se deixou a desejar, $76 \%$ foram notas $8,0,8 \%$ notas $9,0,3 \%$ notas 10,0 e $13 \%$ notas 6,0 , destacaram-se algumas justificativas: "achei a voz muito baixa", "faltou organização do conteúdo apresentado", devido ao tempo disponível para a realização da atividade, o qual é retratado na justificativa a seguir, "só não foi melhor porque a aula durou pouco tempo".

Pode-se com estas análises rever alguns pontos que auxiliarão na busca de melhorias no âmbito de repassar a atividade. A Figura 5 apresenta as notas atribuídas pelos alunos.

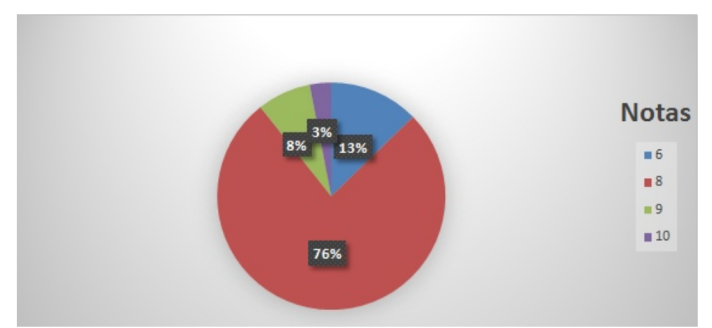

Figura 5: Notas atribuídas pelos alunos para a atividade desenvolvida.

A quinta pergunta solicitava que os discentes expressassem seu ponto de vista sobre a seguinte afirmação: "Novas metodologias aplicadas ao ensino de química contribuem para a aprendizagem e fixação do conteúdo", cerca de $80 \%$ responderam apenas sim, não explicitando sua opinião, apenas $20 \%$ expressaram sua crítica, em que se destacaram algumas: "o uso das imagens no lugar dos símbolos facilitou a compreensão e associação do conteúdo", "mais interessante que a aula do professor", "a matéria dada de outra forma, não sendo no quadro, desperta mais o interesse".

Os dados coletados evidenciaram que a maneira como a aula é conduzida contribui significativamente para a assimilação de conceitos, pois ao permitir que o aluno interaja com um objeto de aprendizado inovador abre-se uma janela para o senso crítico, consequentemente a possibilidade de desenvolver opiniões próprias, mas coerentes com o conteúdo abordado. Assim como também desperta a motivação dos estudantes em relação às aulas de Química, que são sempre consideradas "chatas" e desestimulantes por parte dos discentes. Esse fato da motivação em relação ao gostar de Química ou gostar de aprender Química foi reportado por Cardoso e Colinvaux (2000, p.402), em que tanto

[...] para a motivação quanto para a desmotivação demonstrada no ensino de química, estão basicamente associadas à presença de três fatores: ne- cessidade/não necessidade; facilitada/dificuldade e teoria/prática (forma como é apresentada) sendo estes os fatores que estimulam e motivam o aluno a estudar química.

A inserção de atividades lúdico-pedagógicas durante as aulas para ilustrar um conteúdo, proporcionou como planejamento da aula lúdica, elaboração dos objetivos e serem alcançados pelos alunos, e principalmente a avaliação do desenvolvimento dos alunos no decorrer das atividades. Isso vem ao encontro do considerado por Ciriaco (2009, p.12-13) o qual afirma que aos futuros professores é estabelecido: "competências e habilidades a serem adquiridas na formação inicial, as quais estão associadas á formação pessoal, compreensão da química, busca de informação, comunicação e expressão".

\section{CONCLUSÃO}

De acordo com os dados coletados, pode-se perceber que a atividade pedagógica realizada trouxe resultados significativos quanto à utilização de novas metodologias nas aulas de Química.

A utilização da atividade lúdica permitiu que a aprendizagem do conteúdo fosse realizada de forma mais eficiente, viabilizando ao aluno uma aula dinâmica, menos cansativa e mais produtiva, diminuindo assim a resistência e as dificuldades existentes por parte do aluno em relação aos conhecimentos de Química, incentivando-o a uma autoconstrução do conhecimento e raciocínio lógico (BARATIERI et al., 2008, p.22).

Logo, a inserção desta metodologia acrescentou saberes aos discentes como foi observado anteriormente e também aptidões para os mediadores da atividade, pois as habilidades adquiridas no decorrer da mesma serviram como uma análise, em maior parte positiva acerca do recurso utilizado. E pensando em um futuro como professor, as habilidades adquiridas auxiliarão no desenvolvimento de novas práticas educacionais, bem como no incentivo e utilização das mesmas em busca de um ensino-aprendizado de qualidade.

Portanto o desenvolvimento das atividades pedagógicas intervenção/mediação para ilustrar um conteúdo, proporcionou aos licenciandos experiência como futuros professores de Química, sendo de imensa importância a formação inicial e essencial na busca da qualidade na formação dos docentes no ensino de Química.

\section{REFERÊNCIAS}

ANTUNES, C. Novas formas de ensinar, novas formas de aprender. Artmed, Porto Alegre, p. 7-103, 2002. 
AS CONTRIBUIÇÕES DO PIBID NO ENSINO DE QUÍMICA: ATIVIDADES ALTERNATIVAS A PARTIR DA CONFECÇÃO DE FERRAMENTAS PEDAGÓGICAS PROVENIENTES DE MATERIAIS DE BAIXO-CUSTO

ASTOLFI, J.-P.; DEVELAY, M.; FONSECA, M. S. S. $\quad$ MELO, C. M. R. As atividades lúdicas são A Didática das Ciências. Campinas: Papirus, 1995.

fundamentais para subsidiar ao processo de construção

BARATIERI, S. M.; BASSO, N. R. de S.; BORGES, R. M. R.; FILHO, J. B. da R. OpiniÃo dos estudantes sobre a experimentaÇÃo em quÍmica no ensino mÉdio. Experiências em Ensino de Ciências, v. 3, n. 3, p. 19-31, 2008.

BRASIL, M. L. (Orientações curriculares para o ensino médio). Parâmetros Curriculares Nacionais para o Ensino Médio (PCNEM) - Ciências da Natureza, Matemática e suas Tecnologias. Brasília: MEC, 1999.

. (Orientações curriculares para o ensino médio). Parâmetros Curriculares Nacionais para o Ensino Médio (PCNEM) - Ciências da Natureza, Matemática e suas Tecnologias. Brasília: MEC, 2006.

BROWN, T. L.; JR, H. E. L.; BURSTEN, B. E.; BURDGE, J. R. Química: A Ciência Central. 9. ed. São Paulo: Pearson-Prentice Hall, 2005.

CARDOSO, S. P.; COLINVAUX, D. Explorando a motivação para estudar química. Química Nova, SciELO Brasil, v. 23, n. 3, p. 401-404, 2000.

CIRIACO, M. d. G. S. A formação de professores de química: reflexões teóricas. In: ENCONTRO DE PESQUISA EM EDUCAÇÃO DA UFPI. Teresinha: , 2009.

CUNHA, M. B. da. Jogos no ensino de química: Considerações teóricas para sua utilização em sala de aula. In: QUÍMICA NOVA NA ESCOLA. : QUÍMICA NOVA NA ESCOLA, 2012. v. 34, n. 2, p. 92-98.

DANTAS, L. K. Iniciação à docência na UFMT: Contribuições do PIBID na formação de professores de química. Tese (mathesis) — Programa de Pós-Graduação em Educação, Universidade Federal de Mato Grosso, Cuiabá, 2013.

GIACOMINI, R.; MIRANDA, P.; SILVA, A.; LIGIERO, C. Jogo educativo sobre a tabela periódica aplicado no ensino de química. Revista Brasileira de Ensino de Química, v. 1, n. 1, p. 61-72, 2006.

GODOI, T. A. d. F.; OLIVEIRA, H. P. M. d.; CODOGNOTO, L. Tabela periódica-um super trunfo para alunos do ensino fundamental e médio. Química Nova na Escola, v. 32, n. 1, p. 22-25, 2010.

MALDANER, O. A. A formação inicial e continuada de professores de química: professores/pesquisadores. Unijuí, 2006. 